\title{
Optimal search for binary skew-symmetric sequences with minimal levels of side lobes
}

\author{
Miskiv V.-M. V. ${ }^{1}$, Prudyus I. N. ${ }^{1}$, Fabirovskyy S. Ye. ${ }^{1}$, Pashchuk Yu. M. ${ }^{2}$ \\ ${ }^{1}$ Lviv Polytechnic National University, \\ 12 S. Bandera Str., 79013, Lviv, Ukraine \\ ${ }^{2}$ Hetman Petro Sahaidachny National Army Academy, \\ 32 Heroiv Maidanu Str., 79012, Lviv, Ukraine
}

(Received 11 September 2020; Accepted 1 October 2020)

\begin{abstract}
Signal-code constructions with modulating binary sequences are widely used in multichannel radiocommunication systems, radar, and other information systems. Among these sequences, there are those that provide the minimum levels of side lobes of the aperiodic autocorrelation function and, accordingly, the required secrecy, noise immunity, resolution, and other important characteristics and parameters. The paper describes an alternative approach for solving optimization task that involves a complete full search for the optimal binary skew-symmetric sequences with odd dimension $l$ using a criterion of minimum side lobes of the aperiodic autocorrelation function. The proposed method based on performing two consecutive steps: optimizing in the space of dimension $L<0.5(l-5)$ of the objective functions with respect to the levels of side lobes of the aperiodic autocorrelation function and solving of an equation system which specifies the aperiodic autocorrelation function. The right sides of the equation system present the levels of the side lobes that are obtained as the result of completing the first operation. The developed methodology includes an analysis of the structure of sets of binary sequences; finding correlations between the structural components using the methods of group theory; establishing analytical forms that define the functional relationships between the levels of side lobes of the aperiodic autocorrelation function. The article presents an example of application and results of modeling of the offered algorithm to identify optimal binary sequences.
\end{abstract}

Keywords: binary sequence, aperiodic autocorrelation function, levels of side lobes, complete full search, noise-proof radio systems.

2010 MSC: $68 \mathrm{P} 30$

DOI: $10.23939 / \mathrm{mmc} 2020.02 .410$

\section{Introduction}

The practice of using binary sequences (BS) as modulating functions in radiocommunication, radar, sonar is well known [1-7]. The structure of such BS differs from others because they have minimum levels of side lobes (LSL) of the aperiodic autocorrelation function (AACF). It allows obtaining high rates of secrecy, noise immunity and resolution in these systems. However, the further development of information technology leads to emerging new scientific and technical problems, in particular, the creation of multi-channel noise-proof radio systems for data transmission [8] requires more advanced structures of the BS binary sequences with increased dimension $l$ and the possible minimum of LSL of the aperiodic autocorrelation function.

AACF $A_{k}(a)$ for BS $\{a\}$ is defined as follows $[9,10]$

$$
\begin{gathered}
\{a\}=\left\{a_{1}, a_{2}, \ldots, a_{l}\right\} ; \quad a_{i} \in[-1 ; 1], \quad i \in\{1, \ldots, l\}, \\
A_{k}(a)=\sum_{i=1}^{k} a_{i} a_{l-k+i} ; \quad k \in[1,2, \ldots, l], \quad l=4 m-1 ; \quad m \in\{N\} .
\end{gathered}
$$

where $N$ is a set of natural numbers. 
Initially, the search for optimal structures of BS was described in the articles [11-13]. Later in the paper [14] it has been proved that there is no BS with properties of Barker codes for $13<l<10^{22}$. In the article [9] the most significant scientific achievements in this field were summarized and the directions of further researches were defined. In particular, it pertains to the search of BS with the minimum levels of side lobes. As of now, there are two classes of methods and algorithms:

- full search algorithms (FSA) which allows us to guarantee identification of the optimal BS in a limited time. Herewith, a prerequisite condition is building of search tree of exponential type [10,15];

- metaheuristic algorithms that perform a controlled random search for possible solutions of the combinatorial optimization problem that are close to the optimal ones until a specific termination condition is fulfilled or after reaching a predetermined volume of computational operations [16-18].

Metaheuristic algorithms are much simpler to implement than full search algorithms but generally they do not guarantee the best solution.

In this sense, full search algorithms maintain the best solution, but have an exponential increase in complexity with increasing dimension $l$.

A number of publications have been devoted to the search for compromises and appropriate methods and algorithms $[9,10,13,15,16,18-23]$. Among them, the paper [10] proposes an approach that is based on the analysis of the structure of BS set using the theory of groups and algorithms such as "branch and bound".

Besides, the essential cause for further research is the presence of operations for going over the options to find the optimal binary sequences search in the BS space when using the known methods and algorithms.

\section{Formulation of the problem. Structural relations in a binary sequences set}

During the process of exploring of the BS options within the formed subset, the above mentioned FSAs allows calculating the AACF parameters. Obviously, the acceptance or elimination of binary sequences occurs based on the calculation results for their LSL of the aperiodic autocorrelation function. From this fact, it follows that the known FSAs perform the analysis of "redundant" binary sequences, that are having an LSL with unacceptable value.

This circumstance creates motivation for research and development of alternative FSA type methods and algorithms, which on the one hand would provide a full search for optimal BS, and on the other hand reduce the dimension of the search space due to preliminary screening and eliminating of BS with improper LSL of the aperiodic autocorrelation function.

The purpose of this work is to develop a method and full search algorithm to find optimal skewsymmetric BS that would provide the efficiency estimation $0\left(\varphi^{l}\right)$ efficiency at $1<\varphi<1.63$.

The procedure for solving the formulated task involves the sequential implementation of the following steps:

- identifying subsets of BS according to certain criteria,

- describing the properties BS subsets,

- developing procedures to split the subset of skew-symmetric BS into classes,

- characterizing reflections of classes of skew-symmetric BS into the AACF subset,

- obtaining analytical expressions for the LSL interrelation functions $A_{k}$,

- forming of FSA in the subset of BS of skew-symmetrical type.

It is known $[1,11]$ that allomorphic transformations of BS leave unchanged LSL AACF with the same indices. The operators "addition" (denoted by $C$ ) and "inversion" (denoted by $R$ ) are allomorphic. If we add to them the operator "alternative addition" (denoted by $Q$ ), then their action in the aggregate and in different combinations leaves unchanged modules LSL AACF with the same indices.

The use of algebraic methods and, in particular, the group theory to analyze the BS sets, has been proposed in the works $[10,24,25]$. 
Adding the identity operator $I$, to operators $C, R, Q$ and their combinations form a group $G$ order 8 with group elements

$$
G \in\{I, R, C, Q, R C, R Q, C Q, R C Q\} ; \quad g^{2}=I ;
$$

for all $g \in G$.

The group elements acting on the BS divide the set of all states of the BS into symmetric classes. It should be emphasized that the structure of division into classes depends on the type of BS. In total, the set of BS contains $2^{l}$ sequences that are divided into three subsets:

- symmetrical BSs that contain $2^{0.5(l+1)} \mathrm{BSs}$;

- skew-symmetrical BSs that contain $2^{0.5(l+1)}$ BSs;

- general BSs that contain $2^{l}-2^{0.5(l+3)}$ BSs.

Next, we analyze the subset of skew-symmetric BSs. Action of operators $C$ and $R$ creates classes, each of which contains four BSs. Note that due to the properties of the structure of the BS

$$
a_{i}=-a_{l-i+1},
$$

for $i$ odd;

$$
a_{i}=a_{l-i+1}
$$

for $i$ even, and operator $Q$ action forms the structure, which coincides with the action of the operator $R$. The total number of classes for skew-symmetric BSs is equal to $2^{0.5(l-3)}$. Each class is associated with AACF, which is the image of all BSs of this class, and the modules LSL AACF with the same indices for all BSs of this class are equal.
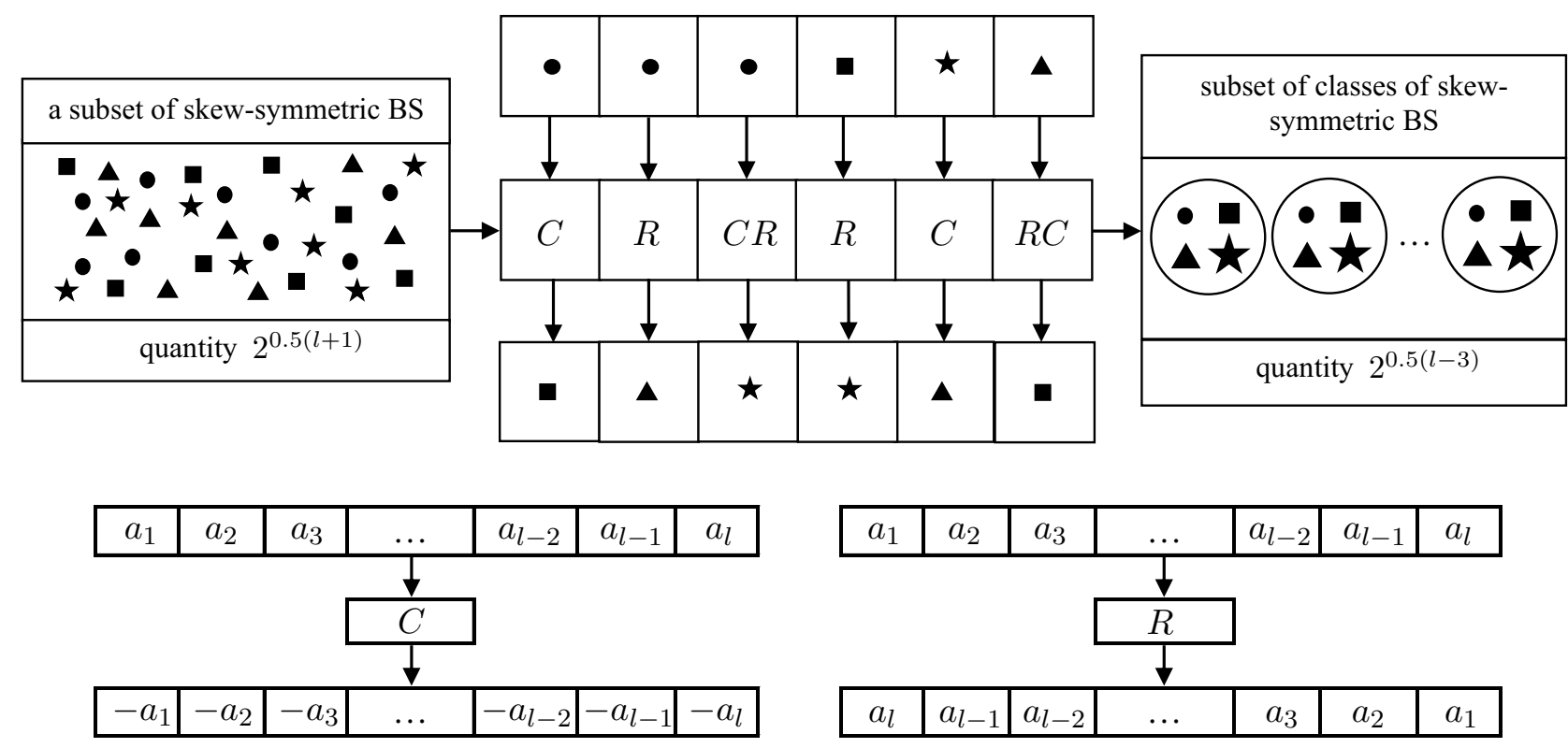

Fig. 1. Formation of classes of binary sequences in the subset of skew-symmetric binary sequences.

The scheme of classes formation for binary sequences in the subset of skew-symmetric binary sequences is depicted in Fig. 1 . We add that due to the properties of the group $G$, that is presented in Fig. 1, the operators $C$ and $R$ may change places. 


\section{Mutual projections and properties of classes of binary sequences and subsets of aperiodic autocorrelation functions}

For further actions it is expedient to present the system of equations (2) in the expanded form, having reduced set of values of parameter $k: k \in\{1,2, \ldots, l-1\}$

$$
\left.\begin{array}{l}
a_{1} a_{l}=A_{1}, \\
a_{1} a_{l-1}+a_{2} a_{l}=A_{2}, \\
a_{1} a_{l-2}+a_{2} a_{l-1}+a_{3} a_{l}=A_{3}, \\
\ldots \ldots \ldots \ldots \ldots \ldots \ldots \ldots \ldots \ldots \ldots \ldots \ldots \ldots \ldots \\
a_{1} a_{l-k+1}+a_{2} a_{l-k+2}+\ldots+a_{k} a_{l}=A_{k}, \\
a_{1} a_{2}+a_{2} a_{3}+\ldots \ldots+a_{l-1} a_{l}=A_{l-1} .
\end{array}\right\}
$$

The value of the dimension $l$ of BS is selected based on the condition

$$
l=1+2 m ; \quad m \in[N] .
$$

where $[N]$ is the set of natural numbers.

The papers [26-28] identify that in the set of BS there is a subset $\Theta$ containing at least one AACF with the maximum of LSL $A_{j}$ satisfying the condition

$$
A_{j}<\sqrt{l}, \quad j \in\{1,2, \ldots, l-1\} .
$$

Let us mark $G_{\Theta}(a)$ a subset of symmetry classes of BS, in which LSL AAKF satisfy (7), and $A_{\Theta}$ is a subset of ordered sequences LSL $\left(A_{1}, A_{2}, \ldots, A_{l-1}\right)$, formed by the projection of the subset $G_{\Theta}(a)$ in LSL AACF by system (5), (6).

Projection of any BS with $G_{\Theta}(a)$ in $A_{\Theta}$ is unambiguous, the projection $A_{\Theta}$ in $G_{\Theta}(a)$ is also unambiguous, however, the reverse projection $A_{\Theta}$ in $\mathrm{BS}$ subsets $G_{\Theta}(a)$ is ambiguous.

It is not an obstacle to find the BS with minimal LSL, since determination of the optimal sequence $\left(A_{1}, A_{2}, \ldots, A_{l-1}\right)$ allows receiving at least one binary sequence from (5), (6). The next step involves identifying of all BSs, which belong to the found class, with using operators $C, R, Q$.

It follows from the above that in order to solve the problem of finding optimal BS through optimization in the sequence space $\left(A_{1}, A_{2}, \ldots, A_{l-1}\right)$ it is necessary to have a function of interconnection of LSL $A_{1}, A_{2}, \ldots, A_{l-1}$. Therefore, the determinant component of the proposed method is obtaining these functions from (5), (6).

It should be noted that the variant for working out the problem by setting all possible values $A_{k}$ in system (5), (6) and the following solving of the equations (with assessment of compatibility this system) is inefficient. It follows from the number of options for searching the LSL $A_{k}$ with odd $k$, which is equal to the product of $1 \cdot 3 \cdot 5 \cdot \ldots \cdot(l-1)$ and exceeds the number of search options $2^{\frac{l}{2}}$ in known FSA for skew-symmetrical binary sequences.

Hence, the interconnection functions of LSL $A_{1}, A_{2}, \ldots, A_{l-1}$ determine the conditions for limiting search for subsets for each $A_{k}$ levels of side lobes.

\section{Interdependencies and structures of sets for levels of side lobes of binary sequences aperiodic autocorrelation functions}

For further transformations, the system (5), (6) is presented, taking into account the properties of the elements of skew-symmetrical BS, as follows 


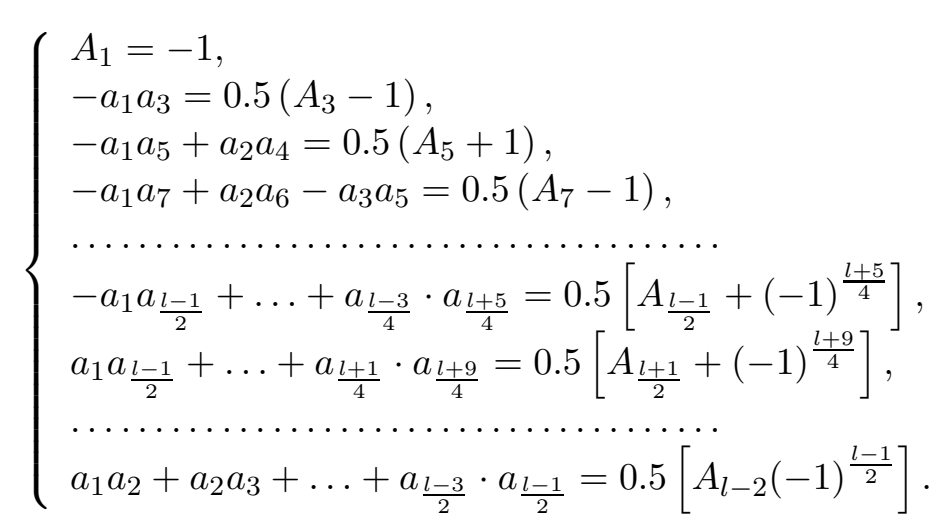

It is necessary to obtain from (8) the following: functional dependencies between values $A_{k} k \in$ $[1 ; 3 ; 5 ; \ldots ; l-2]$, expressions that would determine the structure of sets of valid values, number of independent variables $A_{k}$ in the specified functional dependences, quantity of options of search in space LSL AACF, relationships between parameters of symmetric classes of skew-symmetrical BS and quantity of AACF, which are determined from the obtained functional dependencies.

Representation (8) of system (5), (6) contains only equations with odd values $k$, because as a result of conditions (3), (4) all $A_{k}$ with even $k$ equal to zero. The left parts of each of the equations contain products $a_{i} a_{j}$; further transformations of these equations are performed using these products as functions of $A_{k}$.

Together with the conditions (1), (3), (4), the following procedures are applied with using several properties of products $a_{i} a_{j}$ from (8): the sum of an odd number of items (each item equals to 1 in absolute value) is an odd number; from the expression

$$
a_{i j}+a_{p n}=B_{p}, \quad\left|a_{i} a_{j}\right|=\left|a_{p} a_{n}\right|=1 ; \quad i, j, p, n \in[1,2, \ldots, k] ; \quad i \neq j ; \quad p \neq n ;
$$

follows the next: at $B_{p} \neq 0 \rightarrow a_{i} a_{j}=0.5 B_{p} ; a_{p} a_{n}=0.5 B_{p}$; at $B_{p}=0 \rightarrow a_{i} a_{j}=-a_{p} a_{n}$.

Conditions (3), (4) define the structure of $a_{1}=-a_{l} ; a_{2}=a_{l-1}$, which causes the presence in the BS of two outside elements of the same sign and, on the opposite side of the BS, two outside elements with different signs. This circumstance allows assuming that $a_{1}=a_{2}$ without reducing the generality of reasoning.

Further transformations are performed sequentially for equations with $A_{k} ; k \in[1,3, \ldots, 0.5 l+3]$ and at each step intermediate expressions are defined for $a_{i} a_{j}$, (as functions from $A_{k}$ to substitute them into the following equations) and the structure of subsets of valid values $A_{k}$. The indicated remaining $0.25(l-7)$ equations, after substitution in them $A_{3}, A_{5}, A_{0.5(l-1)}$, form $0.25(l-7)$ objective functions in which $A_{3}, A_{5}, A_{0.5(l+3)}$ they are independent variables, and $A_{k} ; k \in[0.5(l+7), \ldots, l-2]$ are parameters of the AACF LSL, depending on the indicated variables. In general, $0.25(l+5)$ equations from (8) are sequentially involved in these transformations in ascending order of their odd numbers from 1 to $0.5(l+3)$, since these equations contain all $a_{i}, a_{i} \in[1,2, \ldots, l]$.

The products $a_{i} a_{j}$, that are defined in this way and functions from them are substituted in the rest of $0.25(l-7)$ equations with odd $k$ from $0.5(l+7)$ to $l-2$. The given algorithm gives $0.25(l-7)$ functional dependencies $0.25(l-7)$ with odd numbers from $0.5(l+7)$ to $l-2$. Independent variables in the aforesaid functional dependences are $A_{k}$ with odd numbers from 3 to $0.5(l-1)$. Number of independent variables $A_{k}$ does not exceed $0.25(l+1)$, and therefore the number of search options does not exceed $2^{0.25(l+1)}$. When entering an additional upper limit $\sqrt{l}$ for LSL $A_{k} k \in[3 ; 5 ; \ldots ; 0.5(l-1)]$ this number is reduced by at least $33 \%$. Evaluation of effectiveness $\varphi$ of proposed method satisfies the condition $0\left(\varphi^{l}\right) ; 1<\varphi<1.41$.

Part 5 provides a detailed description of the method and algorithm with example for the binary sequence with $l=11$. 


\section{An example of the application of the method and algorithm for finding the optimal binary sequences}

An example of the application of the method and algorithm for finding the optimal BS in the set AACF for $l=11$.

1. The initial system of equations taking into account the conditions (5), (6)

$$
\begin{gathered}
A_{1}=-1 ; \quad a_{1}=a_{2}, \\
-a_{1} a_{3}=0.5\left(A_{3}-1\right), \\
-a_{1} a_{5}+a_{2} a_{4}=0.5\left(A_{5}+1\right), \\
a_{1} a_{5}+a_{2} a_{6}-a_{3} a_{5}=0.5\left(A_{7}-1\right), \\
a_{1} a_{3}+a_{2} a_{4}+a_{3} a_{5}+a_{4} a_{6}=0.5\left(A_{9}+1\right),
\end{gathered}
$$

2. Analysis of transformation of the equations,

2.1. Equation (10). For further substitutions used $a_{1} a_{3}=-0.5\left(A_{3}-1\right)$, and determining the set of valid values of LSL $A_{3}$ is carried out on the basis of the condition $\left|-0.5\left(A_{3}-1\right)\right|=1$. The solution gives $A_{3} \in\{-1 ; 3\} ; A_{3} \neq 1$. The result:

$$
A_{3} \in|-1 ; 3| ; \quad a_{1} a_{3}=-0.5\left(A_{3}-1\right) .
$$

2.2. Equation (11). There are two options for the right part:

2.2.1. $A_{5}=-1 ; a_{5}=a_{4}$

2.2.2. $A_{5}+1 \neq 0 ; a_{2} a_{4}=0.25\left(A_{5}+1\right) ; a_{1} a_{5}=-0.25\left(A_{5}+1\right)$.

The search for a set of values $A_{5}$ is carried out on the basis of the condition $\left|0.25\left(A_{5}+1\right)\right|=1$, and the solution is the set $A_{5} \in\{-5 ; 3\}$. Note: a subset of values can be expanded as a result of consideration of the equations from s. 2.4 and taking into account (sub-s. 2.2.1). Result:

$$
A_{5} \in\{-5 ; 3\} ; \quad a_{2} a_{4}=0.25\left(A_{5}+1\right) ; \quad a_{1} a_{5}=-0.25\left(A_{5}+1\right) .
$$

2.3. Equation (12). The number of items in the left part is odd, therefore $A_{7} \neq 1$. The item $a_{3} a_{5}$ is represented as a product

$$
a_{3} a_{5}=\left(a_{1} a_{3}\right)\left(a_{1} a_{5}\right)=-0.5\left(A_{3}-1\right)\left[-0,25\left(A_{5}+1\right)\right]=0.125\left(A_{3}-1\right)\left(A_{5}+1\right) .
$$

Next equation (12) is presented in the next form: $a_{2} a_{6}=0.5\left(A_{7}-1\right)+0.125\left(A_{3}+1\right)\left(A_{5}+1\right)$. Set of values $A_{7}$ is determined by the condition: $0.5\left(A_{7}-1\right)+0.125\left(A_{3}+1\right)\left(A_{5}+1\right)= \pm 1$. Expression for LSL $A_{7}$, as a function of LSL $A_{3}$ and $A_{5}$ is written as follows:

$$
A_{7}=\left(\begin{array}{c}
+3 \\
-1
\end{array}\right)-0.25\left(A_{3}+1\right)\left(A_{5}+1\right) \text {. }
$$

Since (16) shows that $A_{7}$ is not an independent variable in AACF, the number of options for values $A_{3}, A_{5}, A_{7}$ is equal to the number of variants for values $A_{3}, A_{5}$. Possible combinations of values $A_{3}, A_{5}, A_{7}$ are indicated in Table 1.

The obtained result:

$$
\begin{aligned}
a_{2} a_{6} & =0.5\left(A_{7}-1\right)+0.125\left(A_{3}+1\right)\left(A_{5}+1\right) \\
A_{7} & =\left(\begin{array}{c}
+3 \\
-1
\end{array}\right)-0.25\left(A_{3}+1\right)\left(A_{5}+1\right) .
\end{aligned}
$$

Table 1. Possible combinations of values $A_{3}, A_{5}, A_{7}$.

\begin{tabular}{|c|c|c|c|}
\hline$A_{3}$ & $A_{5}$ & \multicolumn{2}{|c|}{$A_{7}$} \\
\hline-1 & -5 & 3 & -1 \\
\hline-1 & 3 & 3 & -1 \\
\hline 3 & -5 & 7 & 3 \\
\hline 3 & 3 & -1 & -5 \\
\hline
\end{tabular}


2.4. Equation (13).

2.4.1. We will make replacements using the above expressions (14), (15), (16), (17) obtained above

$$
\begin{aligned}
-0.5\left(A_{3}-1\right)+0.25\left(A_{5}+1\right)+0.125\left(A_{3}-1\right) & \left(A_{5}+1\right) \\
& +0.25\left(A_{5}+1\right)\left[0.5\left(A_{7}-1\right)+0.125\left(A_{3}+1\right)\left(A_{5}+1\right)\right] .
\end{aligned}
$$

The result of these substitutions will be two pairs of equations:

$$
\begin{gathered}
\left\{\begin{array}{l}
-0.5\left(A_{3}-1\right)+0.25\left(A_{5}+1\right)+0.125\left(A_{3}-1\right)\left(A_{5}+1\right)+0.25\left(A_{5}+1\right)=0.5\left(A_{9}+1\right), \\
A_{7}=3-0.25\left(A_{3}+1\right)\left(A_{5}+1\right),
\end{array}\right. \\
\left\{\begin{array}{l}
-0.5\left(A_{3}-1\right)+0.25\left(A_{5}+1\right)+0.125\left(A_{3}-1\right)\left(A_{5}+1\right)=0.5\left(A_{9}+1\right), \\
A_{7}=-1-0.25\left(A_{3}+1\right)\left(A_{5}+1\right) .
\end{array}\right.
\end{gathered}
$$

A series of elementary transformations leads these expressions to the next form

$$
\begin{gathered}
\left\{\begin{array}{l}
A_{9}=0.25\left(A_{3}+3\right)\left(A_{5}+1\right)-A_{3}, \\
A_{7}=3-0.25\left(A_{3}+1\right)\left(A_{5}+1\right),
\end{array}\right. \\
\left\{\begin{array}{l}
A_{9}=0.25\left(A_{3}+3\right)\left(A_{5}+1\right)-A_{3}, \\
A_{7}=3-0.25\left(A_{3}+1\right)\left(A_{5}+1\right) .
\end{array}\right.
\end{gathered}
$$

Table 2. Possible combinations of values $A_{3}, A_{5}, A_{7}, A_{9}\left(\right.$ at $\left.A_{5} \neq 0\right)$.

\begin{tabular}{||c|c||c|c||c|c||}
\hline$A_{3}{ }^{*}$ & $A_{5}{ }^{*}$ & $A_{7}$ & $A_{9}$ & $A_{7}$ & $A_{9}$ \\
\hline-1 & -5 & 3 & -1 & -1 & 1 \\
\hline-1 & 3 & 3 & 3 & -1 & 1 \\
\hline 3 & -5 & 7 & 9 & 3 & -7 \\
\hline 3 & 3 & -1 & -3 & -5 & 1 \\
\hline
\end{tabular}

*independent variables (within defined subsets) $A_{3}$, $A_{5}$ in the aperiodic autocorrelation function.
Expressions (18), (19) and subsets of values $A_{3}, A_{5}$, $A_{7}, A_{9}$ show that in the system of equations (8) there are two independent variables $A_{3}, A_{5}$; subsets of values $A_{3}$, $A_{5}$, defined by the first three equations from (8); expressions for substitution in the equation with $A_{9}$ defined in the first five equations of (8).

The total number of AACF obtained from (18), (19) and subsets of independent variables $A_{3}, A_{5}$ is equal to 8. Each of these AACF sets four allomorphic BSs, so the total number of BSs from (18), (19) is equal to 32.

Substituting in (8) the numerical values of the found LSL AACF gives a solution in the form of BS, which is included in one of the classes of symmetry of the set of skew-symmetric BS. The other three BSs of this class are obtained by applying allomorphic operators to the found BS.

2.4.2. Equations (12) and (13). With condition sub-s. 2.2.1, $a_{1} a_{5}+a_{2} a_{6}-a_{3} a_{5}=0.5\left(A_{7}-1\right)$; $A_{7} \neq 1$ and considering (1), (14), an equation (12) is presented in the form:

$$
a_{1} a_{5}\left[0.5\left(A_{3}+1\right)+a_{4} a_{6}\right]=0.5\left(A_{7}-1\right) .
$$

Application of properties $\left|a_{1} a_{5}\right|=1,\left|a_{4} a_{6}\right|=1$ and a series of transformations gives a subset of expressions $A_{7}$ through $A_{3}: A_{7}=A_{3}+4 ; A_{7}=A_{3} ; A_{7}=-A_{3}-2 ; A_{7}=-A_{3}+2$.

Considering appropriate conditions to obtain expressions for $A_{7}$, the expressions and values for $a_{1} a_{3}, a_{2} a_{4}, a_{3} a_{5}, a_{4} a_{6}$ are substituted in (13) and groups of formulas for calculating of LSL $A_{7}, A_{9}$ are derived as functions from $A_{3}, A_{5}$.

$$
\left\{\begin{array} { l } 
{ A _ { 9 } = - 2 A _ { 3 } + 5 , } \\
{ A _ { 7 } = A _ { 3 } + 4 , } \\
{ A _ { 5 } = - 1 , }
\end{array} \quad \left\{\begin{array} { l } 
{ A _ { 9 } = - 1 , } \\
{ A _ { 7 } = A _ { 3 } - 2 , } \\
{ A _ { 5 } = - 1 , }
\end{array} \quad \left\{\begin{array} { l } 
{ A _ { 9 } = - 2 A _ { 3 } + 1 , } \\
{ A _ { 7 } = A _ { 3 } , } \\
{ A _ { 5 } = - 1 , }
\end{array} \quad \left\{\begin{array}{l}
A_{9}=-3, \\
A_{7}=-A_{3}+2, \\
A_{5}=-1 .
\end{array}\right.\right.\right.\right.
$$

Since $A_{3} \in\{-1 ; 3\}$, then each of the resulting expression systems for $A_{5}, A_{7}, A_{9}$ gives two variants of AACF. In total, these are 8 variants of AACF, which are classes of symmetry of skew-symmetrical BS and are shown in Table 3. Together with the AACF, that are described in sub-s. 2.4.1., we obtain 
16 such classes. Each of these classes generates four skew-symmetric binary sequences from system (8). Their total number is 64 . This value coincides with the estimation of the number of skew-symmetrical BSs that are given in Part 2: $2^{6}=64$. This fact confirms that the proposed method and algorithm give the full set of possible values of skew-symmetric BSs and, accordingly, provide a comprehensive search for optimal skew-symmetric BSs. In addition, an important advantage of the proposed method is the possibility for screening and eliminating of unacceptable values at each successive step $A_{k}$, for example, using the criterion $A_{k}<\sqrt{l}$. It allows significantly reducing the number of search options (in general, the degree of this decreasing is determined by the value of the upper limit $\left.A_{\text {limit }} \rightarrow A_{k}<A_{\text {limit }}\right)$.

Table 3. Possible combinations of values $A_{3}, A_{5}, A_{7}, A_{9}$ (at $\left.A_{5}=0\right)$.

\begin{tabular}{||c|c||c|c||c|c||c|c||c|c||}
\hline$A_{3}{ }^{*}$ & $A_{5}{ }^{*}$ & $A_{7}$ & $A_{9}$ & $A_{7}$ & $A_{9}$ & $A_{7}$ & $A_{9}$ & $A_{7}$ & $A_{9}$ \\
\hline-1 & -1 & 3 & 7 & -1 & -1 & -1 & 3 & 3 & -3 \\
\hline 3 & -1 & 7 & -1 & -5 & -1 & 3 & -5 & -1 & -3 \\
\hline
\end{tabular}

*independent variables (within defined subsets) $A_{3}, A_{5}$.

The search for BSs is as follows (an example is given for one of the eight variants of AACF). $A_{3}=3$; $A_{5}=-1 ; A_{7}=3 ; A_{9}=-5$

$$
\left\{\begin{array}{l}
-a_{1} a_{3}=1, \\
-a_{1} a_{5}+a_{2} a_{4}=0, \\
a_{1} a_{5}+a_{2} a_{6}-a_{3} a_{5}=1, \\
a_{1} a_{3}+a_{2} a_{4}+a_{3} a_{5}+a_{4} a_{6}=-2 .
\end{array}\right.
$$

Solving the above system gives one BS from which three more BSs of the found symmetry class are formed according to Fig. 2.

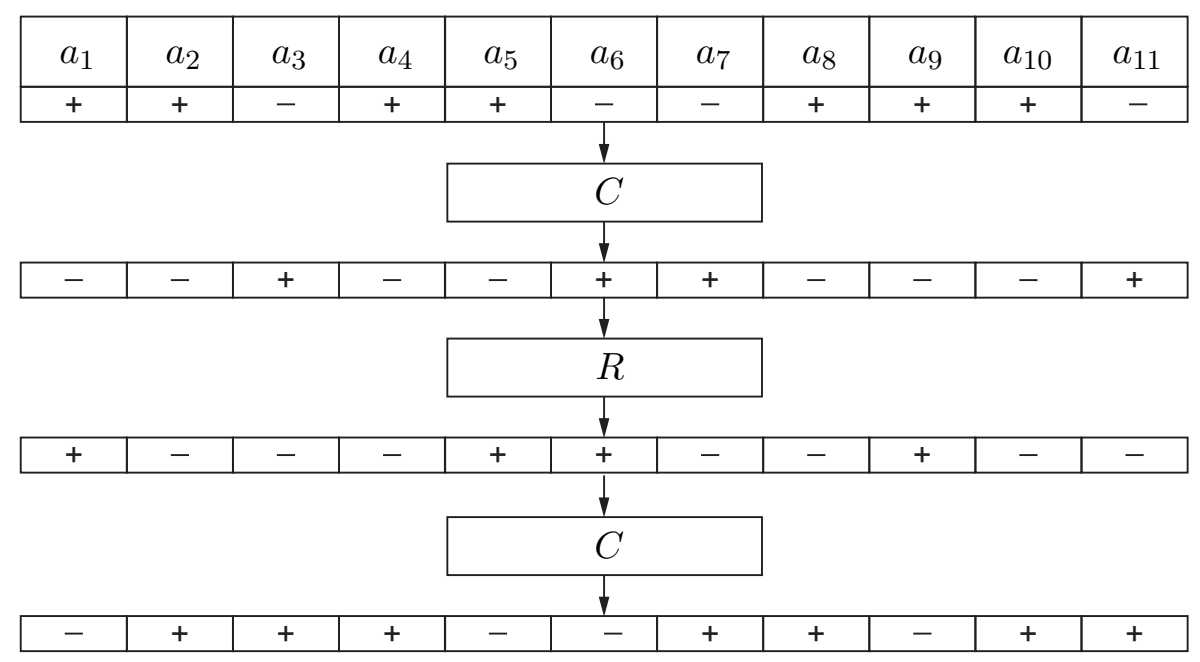

Fig. 2. Formation of binary sequences with aperiodic autocorrelation function.

\section{Conclusion}

In the paper, there are introduced the method and the algorithm to perform the full search for the optimal binary skew-symmetric sequences with odd dimension $l$ using a criterion of minimum side lobes of the aperiodic autocorrelation function. The proposed method is based on performing two consecutive operations: optimizing in the space of dimension $L<0.5(l-5)$ of the objective functions with respect to the levels of side lobes of the aperiodic autocorrelation function; solving of the equation system, which specifies the aperiodic autocorrelation function. The right sides of the equation system present the levels of the side lobes that are obtained as the result of completing the first operation. 
The advantage of the proposed method and algorithm is the possibility of further reducing the dimension $0.5(l-5)$ search space by limiting the upper limit of the levels of side lobes of the aperiodic autocorrelation function with value $\sqrt{l}$.

The suggested methodology is formed on the results of the analysis of the structure of sets of binary sequences; finding correlations between the structure components using the methods of group theory; establishing analytical forms that define the functional relationships between the levels of side lobes of aperiodic autocorrelation function. The article presents an example of application and results of modeling of the proposed algorithm to identify the optimal binary sequences.

[1] Skolnik M. I., Goossens M., Braams J., Carlisle D., Rowley C. Radar Handbook. New York, McGraw-Hill (2008).

[2] Sklar B. Digital Communication. Fundamentals and Application. Prentice Hall (2001).

[3] Varakin L. E. Communication systems with noise-like signals. Moscow, Radio and communication (1985), (in Russian).

[4] Kupriyanov A. I., Shustov L. N. Electronic warfare. Fundamentals of theory. Moscow, University book (2017), (in Russian).

[5] Kuzyk A. Comparative analysis of complex signals based on continuous and discrete frequency modulation. 2016 13th International Conference on Modern Problems of Radio Engineering, Telecommunications and Computer Science (TCSET). 61-63 (2016).

[6] Miskiv A., Miskiv V.-M., Prudyus I., Yankevych R., Fabirovskyy S. Model of the periodic autocorrellation function of code binary sequences for wireless noise imune data transmission systems signals synthesis. 2018 IEEE 4th International Symposium on Wireless Systems within the International Conferences on Intelligent Data Acquisition and Advanced Computing Systems (IDAACS-SWS). 221-224 (2018).

[7] Antonyuk V., Prudyus I., Nichoga V., Kawalec A. Integration of passive coherent radar system into the passive TDOA system. 2012 13th International Radar Symposium. 354-358 (2012).

[8] Combat air strategy: An ambition vision on the future. GOV.uk. https://www.gov.uk/government/ publications/combat-air-strategy-anambitious-vision-for-the-future.

[9] Jedwab J. What can be used instead of a Barker sequence? Contemp. Math. 461, 153-178 (2008).

[10] Packebusch T., Mertens S. Low autocorrelation binary sequences. J. Phys. A: Math. Theor. 49 (16), 165001 (2016).

[11] Barker R. H. Group synchronizing of binary digital systems Communication Theory. In W. Jackson, editor, Communication Theory, Academic Press, New York, 273-287 (1953).

[12] Turyn R., Storer J. On binary sequences. Proc. Amer. Math. Soc. 12, 394-399 (1961).

[13] Schmidt K.-U., Willms J. Barker sequences of odd length. Designs, Codes and Cryptography. 80, 409-414 (2015).

[14] Leung K. H., Schmidt B. The field descent method. Designs, Codes and Cryptography. 36, 171-188 (2005).

[15] Prestwich S. D. Improved Branch-and-Bound for Low Autocorrelation Binary Sequences. Preprint arXiv:1305.6187, 1-9 (2013).

[16] Boškovic B., BrglezF., Brest J. Low-autocorrelation binary sequences: On improved merit factors and runtime predictions to achieve them. Applied Soft Computing. 56, 262-285 (2017).

[17] Mow W. H., Du K., Wu W. H. New evolutionary search for long low autocorrelation binary sequences. IEEE Transactions on Aerospace and Electronic Systems. 51 (1), 290-303 (2015).

[18] Dimitrov M., Baitcheva T., Nikolov N. Efficient Generation of Low Autocorrelation Binary Sequences. IEEE Signal Processing Letters. 27, 341-345 (2020).

[19] Miskiv V.-M. V., Prudyus I. N., Yankevych R. V. Optimization of Code Constructions of Binary Sequences Class on a Basis of Set-Theoretical Representation. Radioelectronics and Communications Systems. 61 (7), 292-305 (2018).

[20] Miskiv V.-M., Kaniewski P., Prudyus I., Konatowski S. Method of synthesis of signal-code constructions for secretive noise-proof data transmission radio systems. XII Conference on Reconnaissance and Electronic Warfare Systems. 11055, 386-392 (2019). 
[21] Matuszewski J. The methods of class pattern forming in order to emitters recognition. Przeglad Elektrotechniczny. 84 (5), 104-108 (2008).

[22] Miskiv V., Prudyus I., Yankevych R. Properties of binary code sequences on the periodical convolution. 2017 International Conference on Information and Telecommunication Technologies and Radio Electronics (UkrMiCo). 1-4 (2017).

[23] Mis'kiv A., Mis'kiv V., Prudyus I., Yankevych R. Discrete sequencies with optimal aperiodic autocorrelation functions. Conditions for existance. 2018 14th International Conference on Advanced Trends in Radioelecrtronics, Telecommunications and Computer Engineering (TCSET). 1264-1267 (2018).

[24] Birkhoff G., Bartee T. C. Modern Applied Algebra. New York, McGraw-Hill (1970).

[25] Goodman S.E., Hedetniemi S. T. Introduction to the Design and Analysis of Algorithms. New York, McGraw-Hill (1977).

[26] Moon J. W., Moser L. On the correlation function of random binary sequences. SIAM J. Appl. Math. 16 (2), 340-343 (1968).

[27] Jedwab J., Yoshida Y. The peak sidelobe level of families of binary sequences. IEEE Transactions on Information Theory. 52 (5), 2247-2254 (2006).

[28] Dmitriev D., Jedwab J. Bounds on the growth rate of the peak sidelobe level of binary sequences. Advances in Mathematics of Communications. 1 (4), 461-475 (2007).

\title{
Оптимальний пошук двійкових кососиметричних послідовностей з мінімальними рівнями бічних пелюстків
}

\author{
Міськів В.-М. В. ${ }^{1}$, Прудиус I. Н. ${ }^{1}$, Фабіровський С. Є. ${ }^{1}$, Пащук Ю. М. ${ }^{2}$ \\ ${ }^{1}$ Національний університет "Лъвівсъка політехніка", \\ вул. С. Бандери, 12, 79013, Лъвів, Украӥна \\ ${ }^{2}$ Національна академія сухопутних війсък імені гетвмана Петра Сагайдачного, \\ вул. Героїв Майдану, 32, 79012, Львів, Україна
}

\begin{abstract}
Сигнально-кодові конструкції з модуляційними двійковими послідовностями широко застосовується в багатоканальних радіосистемах зв'язку, радіолокації та інших системах інформаційного напрямку. Серед зазначених послідовностей особливо виділяються ті, які забезпечують мінімальні рівні бічних пелюстків аперіодичної автокореляційної функції і, відповідно, необхідну скритність, завадостійкість, роздільну здатність та низку інших важливих параметрів. У цій роботі розглядається задача повного пошуку оптимальної, за критерієм мінімуму бічних пелюстків, аперіодичної автокореляційної функції двійкових кососиметричних послідовностей непарної розмірності $l$. Поставлену задачу розв'язано на основі альтернативного підходу та методу, суть якого полягає у проведенні двох послідовних операцій: оптимізації в просторі розмірності $L<0.5(l-5)$ цільових функцій від рівнів бічних пелюстків аперіодичної автокореляційної функції та розв'язування системи рівнянь, яка задає зазначену аперіодичну автокореляційну функцію. При цьому правими частинами системи рівнянь $\epsilon$ рівні бічних пелюстків, знайдені за результатом виконання першої операції. Засади, які покладені в основу запропонованого методу: аналіз структури множин двійкових послідовностей; визначення співвідношень між складовими частинами структури зі застосуванням методів теорії груп; аналітичні вирази, які визначають функціональні взаємозв'язки між рівнями бічних пелюстків аперіодичної автокореляційної функції. Наведено приклад застосування та результати моделювання запропонованого алгоритму пошуку оптимальних двійкових послідовностей.
\end{abstract}

Ключові слова: двійкова послідовність, аперіодична автокореляційна функиія, рівні бічних пелюстків, повний пошук, завадостійкі радіосистеми. 